\title{
IMPERFECTIONS SENSITIVITY ANALYSIS OF STAINLESS STEEL EQUAL-LEGS ANGLE SUBJECTED TO COMPRESSION
}

\author{
FERNANDO R. SARQUIS ${ }^{1}$, LUCIANO R. O. DE LIMA², \\ PEDRO C. G. DA S. VELLASCO ${ }^{3}$ AND ANDRÉ T. DA SILVA ${ }^{4}$ \\ ${ }^{1}$ PGECIV - Civil Engineering Graduate Program, \\ UERJ - State University of Rio de Janeiro, Brazil \\ fernandosarquis@gmail.com \\ ${ }^{2}$ Structural Engineering Department, \\ UERJ - State University of Rio de Janeiro, Brazil \\ luciano@eng.uerj.br \\ ${ }^{3}$ Structural Engineering Department, \\ UERJ - State University of Rio de Janeiro, Brazil \\ vellasco@eng.uerj.br \\ ${ }^{4}$ Structural Engineering Department, \\ UERJ - State University of Rio de Janeiro, Brazil \\ tenchini@eng.uerj.br
}

Keywords: Equal-leg angle, Flexural-torsional buckling, Initial geometrical imperfections, FEM.

\begin{abstract}
This paper presents a numerical analysis of initial geometrical imperfections sensitivity in fixed-end hot-rolled stainless steel 304 equal-leg angle columns under flexuraltorsional buckling. Experimental measurements evidenced that equal-leg angle columns exhibit three initial geometrical imperfections types, specifically: minor-axis bending $\left(d_{m}\right)$, major-axis bending $\left(d_{M}\right)$, and cross-section torsional rotation $(\beta)$. Therefore, using the numerical finite element model in Ansys software, validated with the experimental results, analyses were performed to investigate the influence of the initial geometrical imperfections on the ultimate loads of fixed-end columns failing by flexural-torsional buckling.
\end{abstract}

\section{INTRODUCTION}

Columns with equal-leg angle sections have quite particular structural behaviour. Figure 1(a) shows the cross-section dimensions, width and thickness ( $b$ and $t$ ), in which 1 and 2 are the major and minor principal axes. These structural elements exhibit two failure modes, dependent on the column length: flexural-torsional buckling for short-to-intermediate lengths and minoraxis flexural buckling for long lengths. Regarding flexural-torsional buckling, this phenomenon is associated with a major-axis flexural buckling followed by a cross-section torsional rotation. Figure 1(b) and (c) illustrates the flexural-torsional buckling and minor-axis flexural-buckling, 
respectively. Several works (numerical and experimental) were carried out to investigate the ultimate load of equal-leg angle columns that fails due to the flexural-torsional buckling to establish an accurate and efficient design methodology. Among the studies on carbon steel material, Rasmussen [1], Dinis et al. [2] - [5], Landesmann et al. [6], and Sirqueira et al. [7] can be cited. On the other hand, stainless steel material has been used in numerous constructions due to its high resistance to corrosion, durability, appearance, and aesthetics. Some studies concerning stainless steel equal-leg angle columns can be highlighted: Reynolds [8], Menezes et al. [9], Liang et al. [10], Zhang et al. [11], Sun et al. [12], Sarquis et al. [13], and Sirqueira et al. [14].

Due to this in-depth investigation based on experiments, it could be detected that equal-leg angle columns present three types of initial geometrical imperfections $\left(d_{m}, d_{M}\right.$, and $\beta$ ). Consequently, an imperfection sensitivity study is required to increase this structural element's database and verify whether the columns' ultimate loads prone to flexural-torsional buckling may be sensitive to these types of initial geometrical imperfections.

Consequently, this paper presents a numerical analysis of initial geometrical imperfection sensitivity, validated against two columns experiments made on fixed-ended stainless steel equal-leg angle columns prone to fail by flexural-torsional buckling. Numerical investigations were also made to complete and enlarge the database.
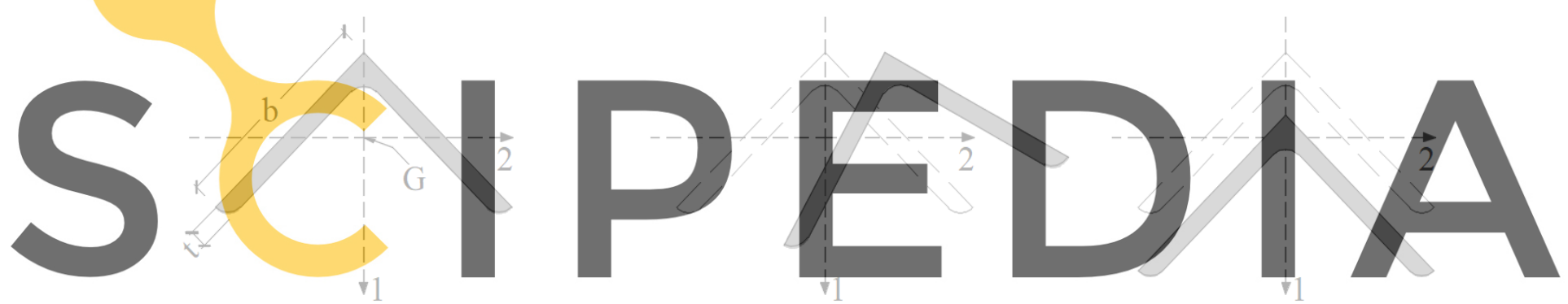

Register for fre b) download the version without the watermark Figure 1: a) Equal-leg angle section, b) Flexural-torsional buckling, and c) Minor-axis flexural buckling.

\section{INITIAL GEOMETRICAL IMPERFECTIONS IN EQUAL-LEG ANGLES}

According to the developed methodology, it is possible to measure the initial geometrical imperfections throughout the equal-leg angle columns with four displacement transducers' (DTs) readings. These procedures are described in detail in Landesmann et al. [6] and are briefly compiled in this paper.

Figure 2(a) shows the DT1-4 positioned on a reference cross-section, where $\mathrm{y}_{1}, \mathrm{y}_{2}, \mathrm{x}_{3}$, and $\mathrm{x}_{4}$ are the distances from the leg's corner in the X-Y plane. These four DTs' measurements and positions are used to assess the initial geometrical imperfections. Figure 2(b) shows a crosssection with the initial geometrical imperfections (deformed): $\beta$ is the initial cross-section torsional rotation (i.e., local imperfection); $d_{M}$ and $d_{m}$ are the translations of the leg's corner about the principal axes (i.e., global imperfection), defining a major-axis and minor-axis flexural buckling, respectively. It is worth mentioning that the initial cross-section torsional rotation angle $(\beta)$ is assumed positive when clockwise. The experimental data acquisition, illustrated in Figure 2(c), is performed employing four displacement transducers (DT1-4), a wire-type displacement transducer (DT5) and a milling machine (rigid table). The column is 
positioned on the rigid table (only moving horizontally), containing DT1-4 along the column length outer surface (reference cross-section). The DT5 is used to obtain the horizontal displacement as the rigid table moves, and consequently, it can map how each cross-section vary along the column length. Highlighting that the DT1-4 remains fixed, whereas the rigid table moves horizontally.

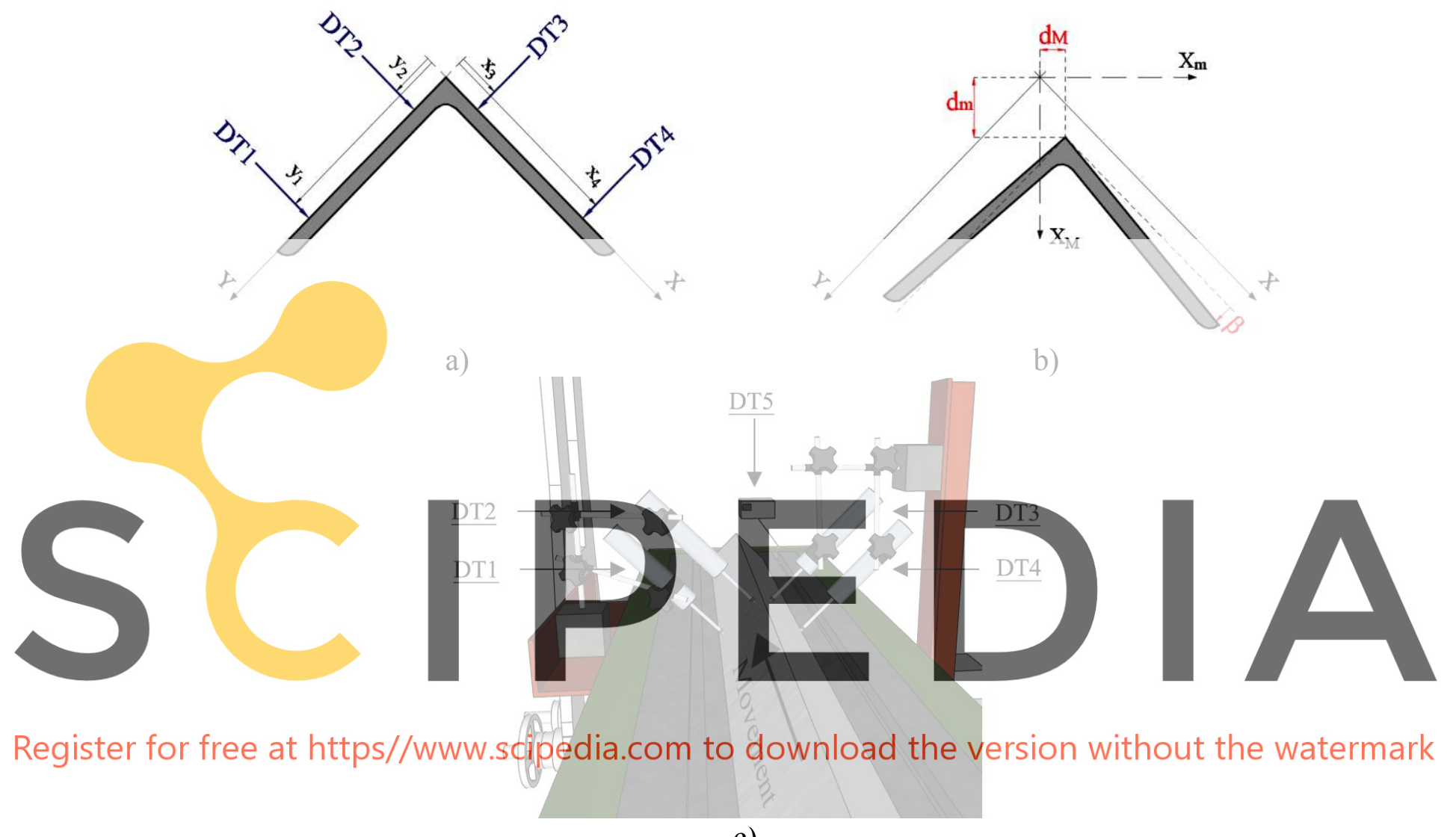

c)

Figure 2: Initial geometrical imperfections measurements a) cross-section reference and DTs location; b) crosssection "deformed" configuration; c) experimental set-up.

\section{FIXED-ENDED EQUAL-LEG ANGLE COLUMN SELECTION}

In order to investigate the influence of the initial geometrical imperfections on the flexuraltorsional buckling of fixed-ended austenitic stainless steel 304 (EN 1.4301) equal-leg angle columns, two columns were selected from the experimental investigation conducted at the Rio de Janeiro State University (UERJ). This experimental campaign consisted of: a selection of cross-section dimensions and lengths for the fixed-ended columns; material characterization (compression and tensile); initial geometrical imperfections measurements to establish the local $(\beta)$ and global $\left(d_{m}\right.$ and $\left.d_{M}\right)$ imperfections of the columns; ultimate load and failure mode. A complete description of these procedures and tests can be found in [6]. 


\subsection{Columns selections}

The columns selection criteria consisted of the following aspects: vary the cross-section dimensions, i.e., $b / t$ ratio; same initial geometrical imperfection sign combination; columns including the largest and the smallest amplitude measured experimentally for minor-axis flexural imperfection $\left(d_{m}\right)$. It was possible to fulfil the specified conditions, and two columns

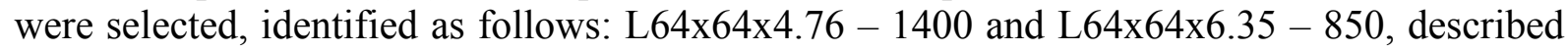
by the cross-section dimensions ( $b$ and $t$ ) and the nominal column length $(L)$.

Table 1 presents for each column, the cross-section and nominal lengths, the sign and maximum values assessed for initial geometrical imperfections measurements, and also experimental ultimate loads $\left(N_{u, \exp }\right)$. Figure 3 illustrates the calculated initial geometrical imperfections along the column length. It could be noted that the primary vertical axis represents the major and minor-axis flexural ( $d_{M}$ and $d_{m}-$ global imperfections), and the secondary vertical axis represents the cross-section rotation $(\beta$-local imperfection); the horizontal axis is associated to the cross-section normalized position $(D T 5 / L)$. An assessment of the amplitude values present in Table 1 and the results illustrated in Figure 3 suggests the following observations: L64x64x4.76 - 1400 column exhibited a minor-axis flexural $\left(d_{m}\right)$ magnitude higher than L/1000, specifically L/769 (1.82 > 1.40); the L64x64x6.35 - 850 column presented a minor-axis flexural $\left(d_{m}\right)$ significantly lower than L/1000, specifically L/5312 $(0.16<0.85)$; initial cross-section torsional rotations are relatively small; also, it was possible to conclude that all displacement contours in Figure 3 exhibit a predominant single
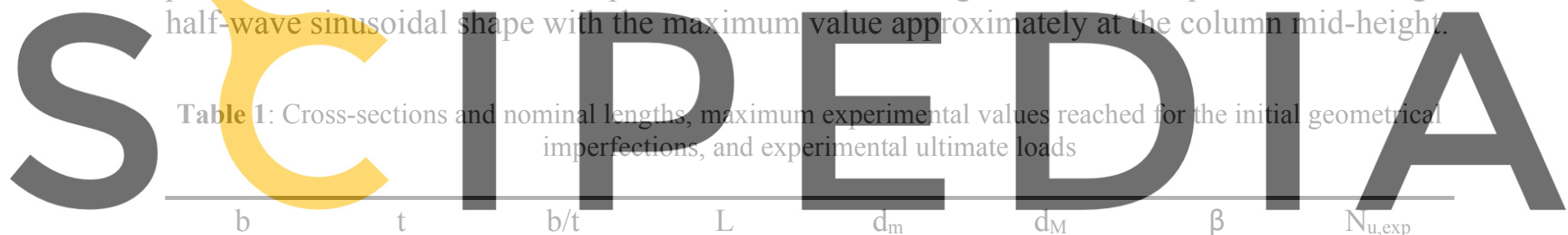

$(\mathrm{mm}) \quad(\mathrm{mm}),(\mathrm{mm}) \quad(\mathrm{mm}) \cdot\left(\mathrm{rad} \times 10^{-2}\right) \cdot(\mathrm{kN})$

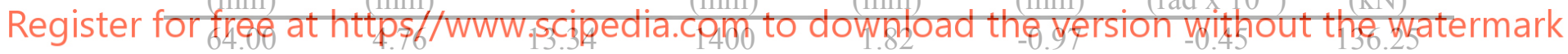

\begin{tabular}{llllllll}
64.00 & 6.35 & 10.00 & 850 & 0.16 & -0.43 & -0.48 & 226.45 \\
\hline
\end{tabular}

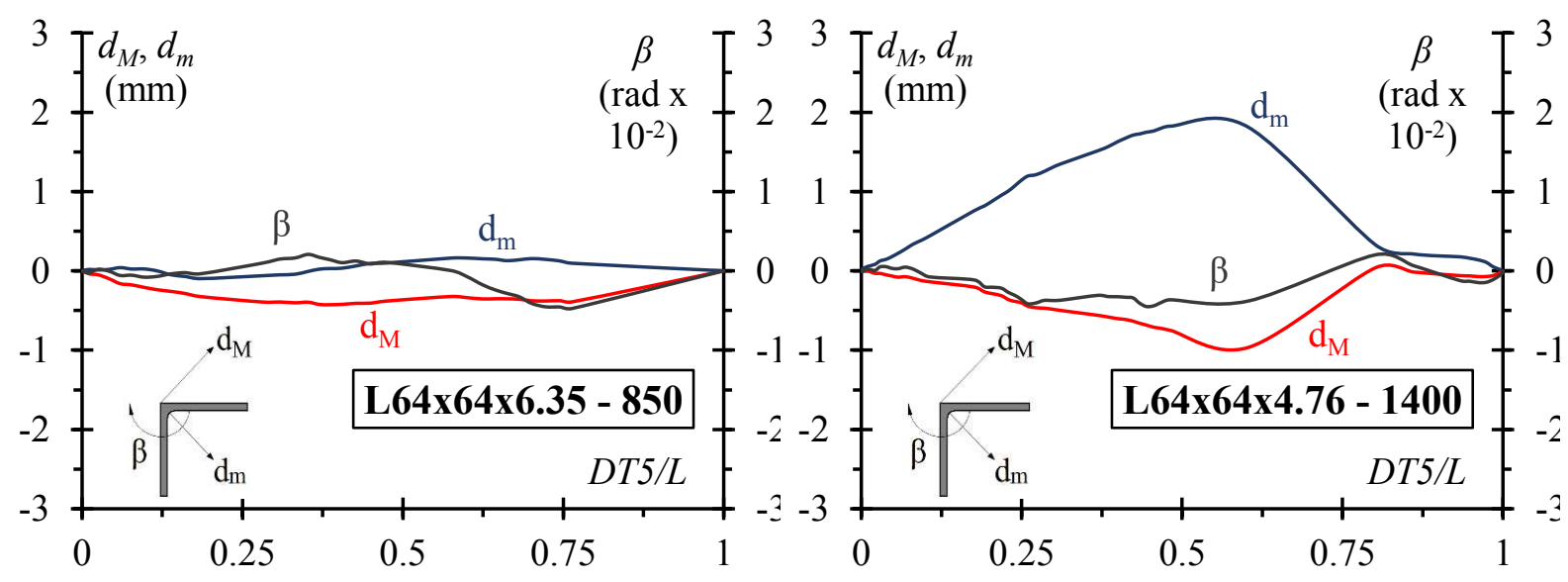

Figure 3: Experimental initial geometrical imperfections measurements for the columns selected. 


\section{NUMERICAL ANALYSIS}

The main aim of this paper is to verify, through a numerical investigation, the influence of the initial geometrical imperfections in fixed-ended austenitic stainless steel 304 (EN 1.4301) equal-leg angle columns prone to fail by flexural-torsional buckling. Therefore, three steps were considered: i) finite element model validation with the experimental results; ii) the influence of initial geometrical imperfection sign combinations with amplitudes commonly applied in numerical investigations; iii) sensitivity study divided into three imperfections combinations with five amplitude values for the initial cross-section torsional rotations.

\subsection{Finite element model development}

The numerical analysis was performed in ANSYS 17.0 software [15] using SHELL181 finite element (present in Ansys's library) with four nodes, including six degrees of freedom per node and full integration.

The 304 austenitic stainless steel was characterized by a stress versus strain curve related to the material experimental average curves [13]. Twenty-two points were inserted in the finite element models to characterize the material nonlinearities, as shown in Figure 4(a), and the approximate mechanical properties values were: Young's modulus ( $E=208 \mathrm{GPa})$; stress corresponding to a $0.2 \%$ strain $\left(\sigma_{0.2 \%}=305 \mathrm{MPa}\right)$; Poisson coefficient $(v=0.3)$.

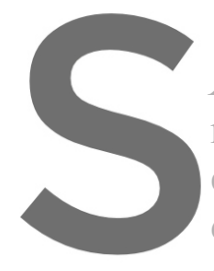

Cross-section georne

$\left.X_{M}\right)$ and parallel to the

rigid links connected

conditions were imposed on

displacements and rotat
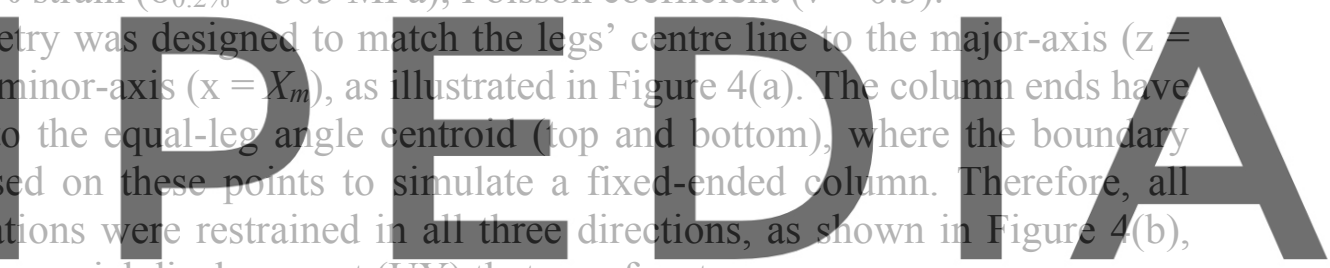

except for the column top axial displacement (UY) that was free to move.

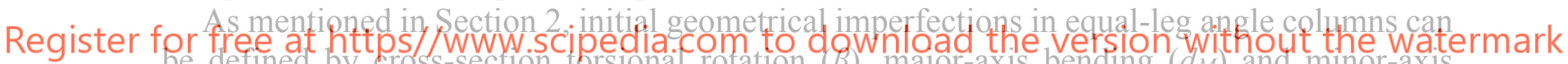
bending $\left(d_{m}\right)$. The initial geometrical imperfections were inserted into the finite element model through three elastic buckling analyses (eigenvectors). This makes it possible to establish the amplitude and sign individually for each type of initial geometrical imperfection. First, the corner nodes of the column were restrained from moving at x and z-axis; consequently, only cross-section rotation was allowed, and thus, the imperfection of the rotation was assessed, as illustrated in Figure 5(a). Next, all column's nodes were restrained from moving on the z-axis, forcing the column to fail by a major-axis flexural buckling, as illustrated in Figure 5(b). For minor-axis flexural buckling, the same procedure was made, but all nodes were restrained from moving on the x-axis, as illustrated in Figure 5(c). Highlighting that each buckling analysis did not affect the others, i.e., the straight equal-leg angle column was simultaneously updated using the "UPGEOM" Ansys command.

Finally, the load was applied by a prescribed displacement (UY) at the upper column end centroid, and the nonlinear analysis was performed using an incremental-iterative method based on the Newton-Raphson algorithm, concerning the material and geometrical nonlinearities. A mesh convergence study led to a $5 \mathrm{~mm}$ x $5 \mathrm{~mm}$ element size that provided an excellent correlation with the experimental behaviour, requiring a fair computational effort. 


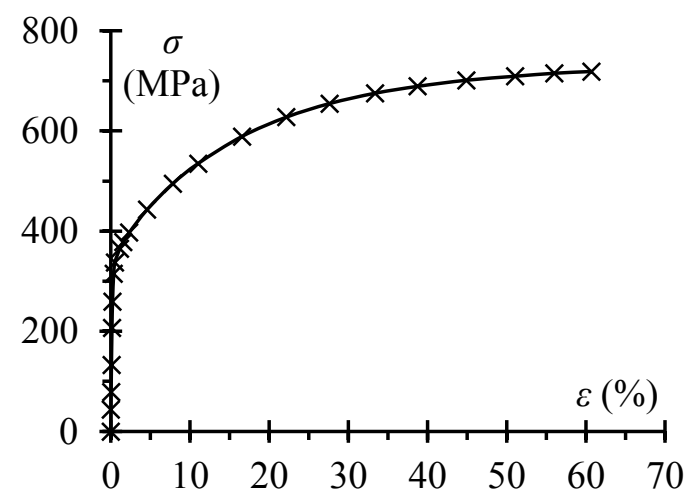

a)

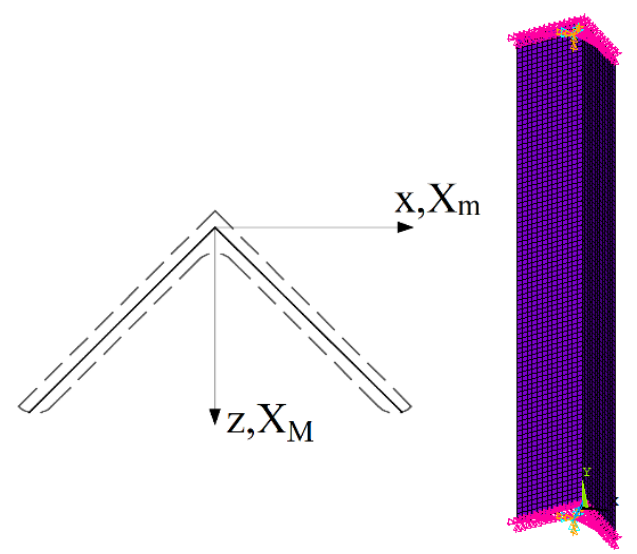

b)

Figure 4: a) Austenitic stainless steel 304 stress-strain curve employed b) cross-section and column ends.
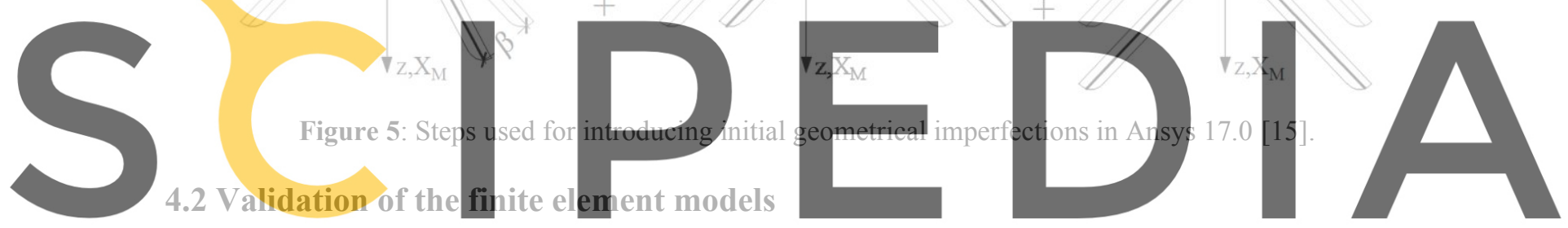

The validation of the finite element models for the investigated fixed-end austenitic stainless

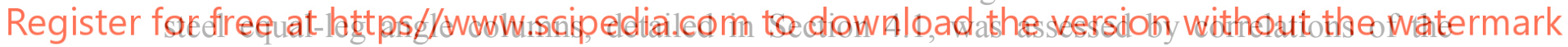
numerical with experimental results in terms of ultimate loads, load vs axial displacement curves and failure modes.

Table 2 presents the experimental $\left(\mathrm{N}_{\mathrm{u}, \exp }\right)$ and numerical $\left(\mathrm{N}_{\mathrm{u}, \mathrm{FE}}\right)$ ultimate loads and its ratio. Figure 6 shows the finite element model accuracy in terms of the load $v s$ axial displacement

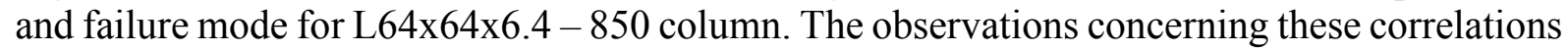
indicated: i) reliable ultimate load predictions; ii) the entire load $v s$ displacement curve could be represented by the finite element model; iii) and an excellent agreement was also achieved in terms of the failure modes.

Table 2: Experimental and numerical ultimate loads.

\begin{tabular}{|c|c|c|c|c|}
\hline Column & $\begin{array}{l}\text { Boundary } \\
\text { condition }\end{array}$ & $\begin{array}{c}\mathrm{N}_{\text {u.exp }} \\
(\mathrm{kN})\end{array}$ & $\begin{array}{c}\mathrm{N}_{\mathrm{u} . \mathrm{FE}} \\
(\mathrm{kN})\end{array}$ & $\frac{N_{u . F E}}{N_{\text {u.exp }}}$ \\
\hline L64x64x6.4-850 & $\mathrm{FF}$ & 226.45 & 216.43 & 0.96 \\
\hline L64x64x4.8-1400 & FF & 136.25 & 137.29 & 1.01 \\
\hline
\end{tabular}




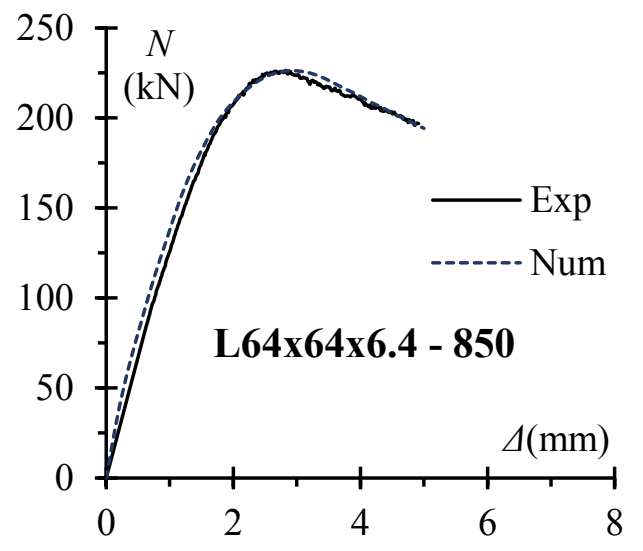

a)

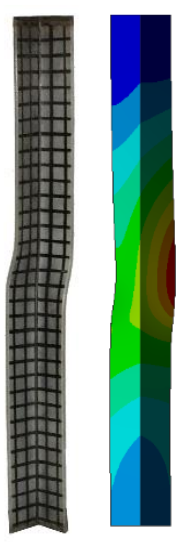

b)

Figure 6: L64×64×6.4 - 850 column experimental and numerical results a) load $v s$ axial displacement curves and b) failure modes.

\subsection{Initial geometrical imperfections sign combinations}

As aforementioned in Section 2, there are three initial geometrical imperfections in equalleg angle columns, and each of them can own positive or negative sign, as shown in Figure 2(b). Therefore, the influence of the sign in the initial cross-section torsional rotation (local) and global imperfections on the fixed-ended austenitic stainless steel equal-leg angle columns was investigated in the finite element model. Consequently, to only check the influence of the sign, eight combinations were taken into account previous studies [6], [7], [10]) but varying the rotation; ii) L/1000 for the major-axis bending

Table 3 presents the amplitude and sign
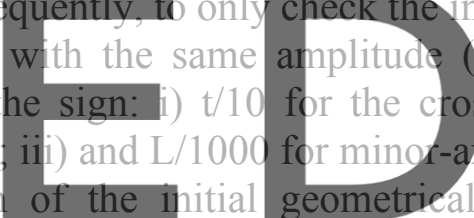

L64x64x6.4 - 850 column. The results show that there is no notable difference in the ultimate

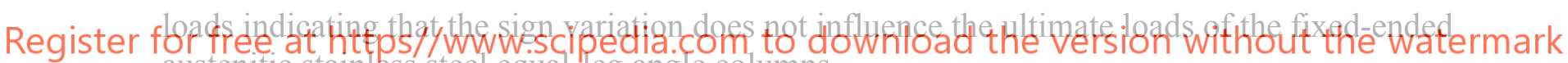
austenitic stainless steel equal-leg angle columns.

Table 3: Initial geometrical imperfections values and sign, and ultimate numerical loads.

\begin{tabular}{cccccc}
\hline Column & Combination & $\begin{array}{c}\mathrm{d}_{\mathrm{m}} \\
(\mathrm{mm})\end{array}$ & $\begin{array}{c}\mathrm{d}_{\mathrm{M}} \\
(\mathrm{mm})\end{array}$ & $\begin{array}{c}\beta \\
(\mathrm{rad})\end{array}$ & $\begin{array}{c}\mathrm{N}_{\mathrm{u}, \mathrm{FE}} \\
(\mathrm{kN})\end{array}$ \\
\hline & 1 & 0.85 & 0.85 & 0.0141 & 232.03 \\
& 2 & 0.85 & 0.85 & -0.0141 & 234.79 \\
& 3 & 0.85 & -0.85 & 0.0141 & 234.79 \\
L64x64x6.4-850 & 4 & 0.85 & -0.85 & -0.0141 & 232.03 \\
& 5 & -0.85 & 0.85 & 0.0141 & 232.31 \\
& 6 & -0.85 & -0.85 & 0.0141 & 234.94 \\
& 7 & -0.85 & 0.85 & -0.0141 & 234.94 \\
& 8 & -0.85 & -0.85 & -0.0141 & 232.31 \\
\hline
\end{tabular}




\subsection{Initial geometrical imperfection sensitivity}

The initial geometrical imperfection sensitivity investigation of fixed-ended stainless steel equal-leg angle columns involves a comparison of the ultimate loads and load $v s$ axial displacement curves for the two selected columns. The measured imperfection amplitudes, as described in 3.1, were employed in the finite element model as a reference for the investigation (validation study - VS), and also for the experiments.

This imperfection sensitivity study comprises five amplitude values for the initial crosssection torsional rotation $(\beta)$, specifically $t / 20, t / 15, t / 10, t / 5$, and $t$. Besides, for each adopted amplitude value, the investigation was divided into three combinations:

i) first, through three elastic buckling analyses, the experimentally measured imperfections values were maintained for minor and major-axis bending $\left(d_{m}\right.$ and $\left.d_{M}\right)$ with increasing amplitudes for cross-section torsional rotation $(\beta)$;

ii) second, through two elastic buckling analyses, the experimentally measured imperfection value was maintained for minor-axis bending $\left(d_{m}\right)$ with increasing amplitudes for flexural-torsional buckling mode (FT);

iii) third, through one elastic buckling analyses, only flexural-torsional buckling mode (FT) with increasing amplitudes was analyzed.

It is crucial to highlight that to obtain the initial cross-section torsional rotation amplitude adopted values, the Ansys' flexural-torsional buckling mode (FT) presents only a minute amplitude for major-axis flexural buckling. Therefore, in this way, it is possible to assess the

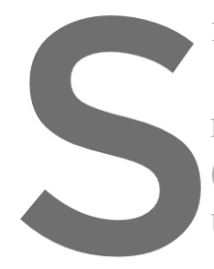
influence of each initial

Table 4 and Table 5 numerical load $\left(N_{u, F E}\right)$ $\left(N_{u, F E} / N_{u, e x p}\right)$ for $\mathrm{L} 64 \times 64 \times 6.3$ ultimate loads, the observation
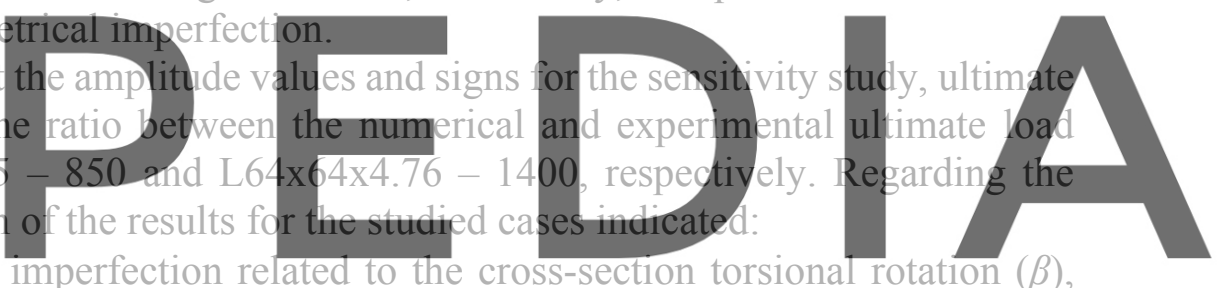

- Concerning the initial imperfection related to the cross-section torsional rotation $(\beta)$, Register for free aty the case where an amplitude value equal to "t" presented influence over the

$t / 20$ and $t$ values in analyses iii of the column L64x64x6.35 - 850 was observed, revealing that the cross-section torsional rotation initial imperfection does not have a significant influence over the ultimate loads. It is important to note that the typical value employed in numerical analyses for local imperfection is $t / 10$;

- When comparing analyses $i$ and ii for the two columns, it was verified that the ultimate loads in both analyses are quite similar. These results are suggesting that the major-axis flexural bending amplitude $\left(d_{M}\right)$ has no impact on the ultimate loads;

- On the other hand, by comparing the three investigated analyses (i, ii, and iii) for the two columns, it is possible to verify that the minor-axis flexural buckling $\left(d_{m}\right)$ exhibits influence in the ultimate load, regardless of its amplitude ( 0.16 or 1.82$)$. Emphasizing that 0.16 and 1.82 amplitude values mean L/5312 and L/769, respectively, and the standard value adopted in the design codes is $\mathrm{L} / 1000$.

Figure 7 shows the load $v s$ axial displacement curves of the three analyses performed (i, ii

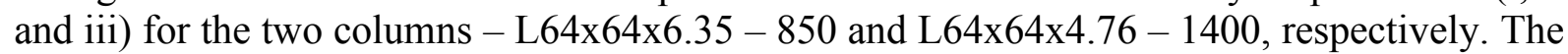
observations of these curves make it possible to conclude that for the experimental curve load $v s$ axial displacement to be entirely captured by the numerical simulation; the three initial 
geometrical imperfections must be inserted in the finite element model $\left(\mathrm{d}_{\mathrm{m}}, \mathrm{d}_{\mathrm{M}}\right.$, and $\left.\beta\right)$. Also, it can be noted the effect in the ultimate load of adding the minor-axis flexural buckling $\left(d_{m}\right)$.

Table 4: Imperfection sensitivity study for column L64x64x6.35 - 850 .

\begin{tabular}{|c|c|c|c|c|c|c|c|}
\hline \multirow{2}{*}{$\begin{array}{c}\text { Investigation } \\
\text { VS }\end{array}$} & \multirow{2}{*}{$\frac{\begin{array}{c}\mathrm{d}_{\mathrm{m}} \\
(\mathrm{mm})\end{array}}{0.16}$} & \multirow{2}{*}{$\begin{array}{c}\begin{array}{c}\mathrm{d}_{\mathrm{M}} \\
(\mathrm{mm})\end{array} \\
-0.43 \\
\end{array}$} & \multirow{2}{*}{$\begin{array}{c}\beta \\
(\mathrm{rad}) \\
-0.0048\end{array}$} & \multicolumn{2}{|c|}{$\begin{array}{l}\text { Amplitude } \\
(\mathrm{mm})\end{array}$} & \multirow{2}{*}{$\begin{array}{c}\mathrm{N}_{\mathrm{u}, \mathrm{FE}} \\
(\mathrm{kN}) \\
226.27\end{array}$} & \multirow{2}{*}{$\frac{\mathrm{N}_{\mathrm{u}, \mathrm{FE}} / \mathrm{N}_{\mathrm{u}, \exp }}{0.99}$} \\
\hline & & & & 0.21 & $\mathrm{t} / 29$ & & \\
\hline \multirow{5}{*}{$\mathrm{i}$} & 0.16 & -0.43 & -0.0071 & 0.31 & $t / 20$ & 226.19 & 0.99 \\
\hline & 0.16 & -0.43 & -0.0094 & 0.42 & $t / 15$ & 225.67 & 0.99 \\
\hline & 0.16 & -0.43 & -0.0141 & 0.63 & $\mathrm{t} / 10$ & 224.53 & 0.99 \\
\hline & 0.16 & -0.43 & -0.0283 & 1.27 & $t / 5$ & 220.56 & 0.97 \\
\hline & 0.16 & -0.43 & -0.1414 & 6.35 & $\mathrm{t}$ & 192.66 & 0.85 \\
\hline \multirow{9}{*}{ ii } & 0.16 & -0.015 & -0.0070 & 0.31 & $t / 20$ & 231.82 & 1.02 \\
\hline & 0.16 & -0.019 & -0.0093 & 0.42 & $t / 15$ & 231.73 & 1.02 \\
\hline & 0.16 & -0.029 & -0.0139 & 0.63 & $t / 10$ & 231.49 & 1.02 \\
\hline & 0.16 & -0.058 & -0.0279 & 1.27 & $\mathrm{t} / 5$ & 230.27 & 1.01 \\
\hline & 0.16 & -0.292 & -0.1510 & 6.35 & $\mathrm{t}$ & 201.18 & 0.88 \\
\hline & 0.00 & -0.015 & -0.0070 & 0.31 & $t / 20$ & 260.94 & 1.15 \\
\hline & 0.00 & -0.019 & -0.0093 & 0.42 & $t / 15$ & 253.86 & 1.12 \\
\hline & 0.00 & -0.029 & -0.0139 & 0.63 & $\mathrm{t} / 10$ & 252.30 & 1.11 \\
\hline & 0.00 & $-0,058$ & -0.0279 & 1.27 & $1 / 5$ & 245.22 & 1.08 \\
\hline & .00 & & & & & & \\
\hline & & & & & & & \\
\hline
\end{tabular}

$(\mathrm{mm}) \quad(\mathrm{mm}) \quad(\mathrm{mad}) \quad(\mathrm{mm})$

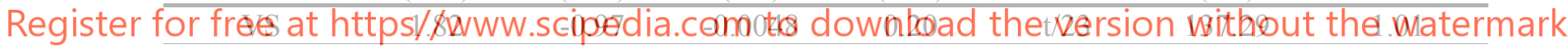

\begin{tabular}{cccccccc} 
& 1.82 & -0.97 & -0.0053 & 0.23 & $\mathrm{t} / 20$ & 137.05 & 1.01 \\
\multirow{4}{*}{ i } & 1.82 & -0.97 & -0.0071 & 0.31 & $\mathrm{t} / 15$ & 136.48 & 1.00 \\
& 1.82 & -0.97 & -0.0106 & 0.47 & $\mathrm{t} / 10$ & 134.69 & 0.99 \\
& 1.82 & -0.97 & -0.0212 & 0.95 & $\mathrm{t} / 5$ & 134.12 & 0.98 \\
& 1.82 & -0.97 & -0.1060 & 4.76 & $\mathrm{t}$ & 127.24 & 0.93 \\
\hline \multirow{3}{*}{ ii } & 1.82 & -0.016 & -0.0053 & 0.23 & $\mathrm{t} / 20$ & 135.05 & 0.99 \\
& 1.82 & -0.021 & -0.0071 & 0.31 & $\mathrm{t} / 15$ & 135.00 & 0.99 \\
& 1.82 & -0.031 & -0.0107 & 0.47 & $\mathrm{t} / 10$ & 134.85 & 0.99 \\
& 1.82 & -0.062 & -0.0214 & 0.95 & $\mathrm{t} / 5$ & 134.14 & 0.98 \\
\multirow{3}{*}{ iii } & 1.82 & -0.312 & -0.0980 & 4.76 & $\mathrm{t}$ & 122.27 & 0.89 \\
& 0.00 & -0.016 & -0.0053 & 0.23 & $\mathrm{t} / 20$ & 154.87 & 1.13 \\
& 0.00 & -0.021 & -0.0071 & 0.31 & $\mathrm{t} / 15$ & 153.26 & 1.12 \\
& 0.00 & -0.031 & -0.0107 & 0.47 & $\mathrm{t} / 10$ & 151.94 & 1.11 \\
& 0.00 & -0.062 & -0.0214 & 0.95 & $\mathrm{t} / 5$ & 150.40 & 1.10 \\
& 0.00 & -0.312 & -0.0980 & 4.76 & $\mathrm{t}$ & 124.98 & 0.91 \\
\hline
\end{tabular}



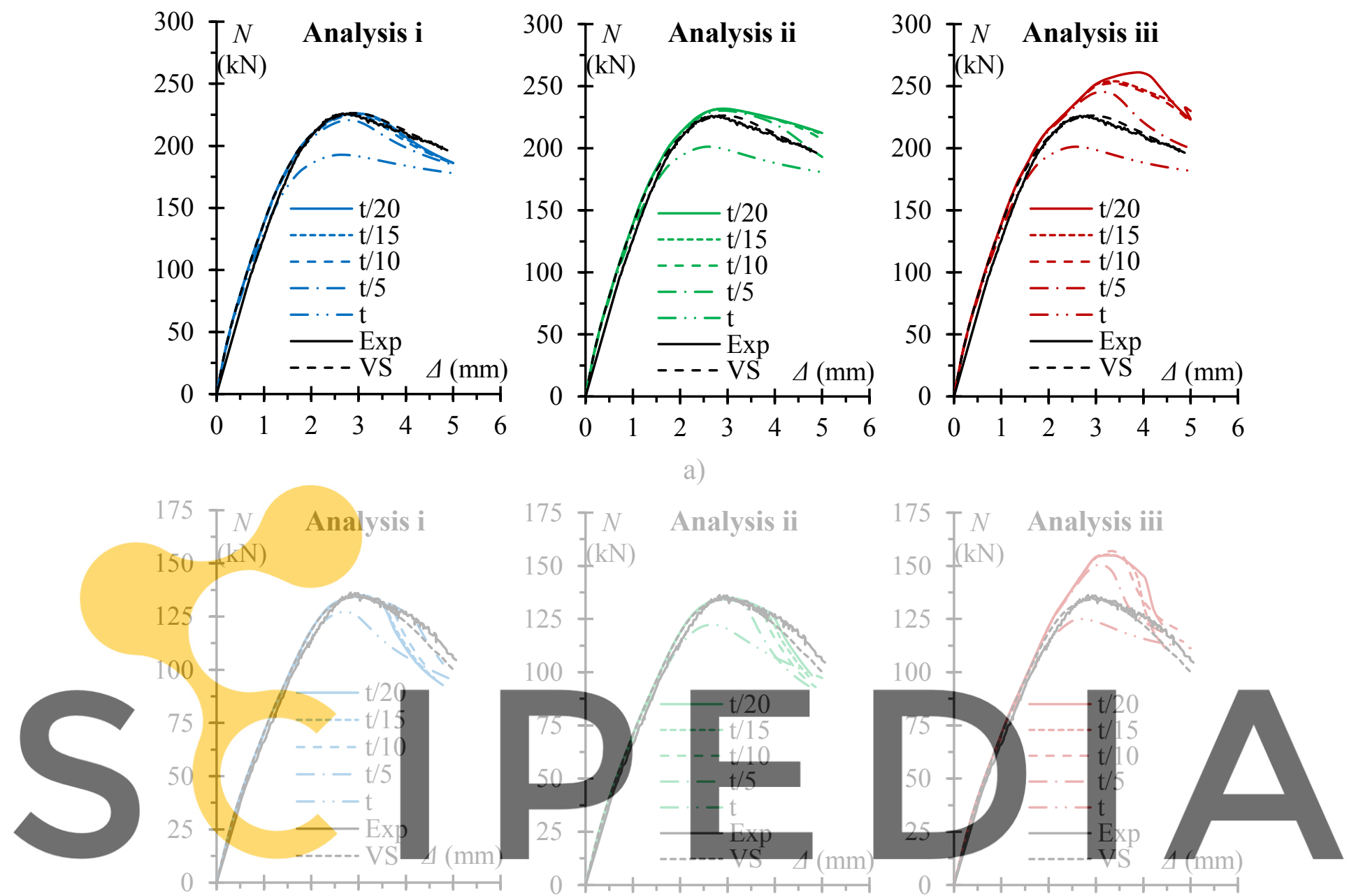

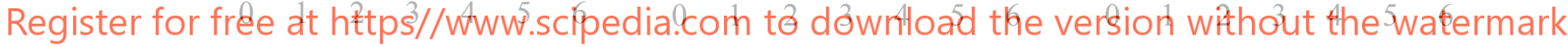

Figure 7: Numerical load vs axial displacement curves obtained in the three analyses imperfection-sensitivity study a) L64x64x6.35 - 850 and b) L64x64x4.76 - 1400.

\section{CONCLUSIONS}

A numerical investigation was carried out to study the influence of the initial geometrical imperfections in fixed-ended austenitic stainless steel 304 (EN 1.4301) equal-leg angle columns prone to flexural-torsional buckling. Finite element models were developed and validated against experiments and were used to produce additional numerical results.

The numerical results achieved show that in fixed-ended equal-leg angle columns, there are no signs combinations unfavourable, i.e., for the same amplitude values but changing the signs, no notable difference in the ultimate loads was checked. However, when analyzing the three initial geometric imperfections, it could be concluded that, despite the columns being subjected to flexural-torsional buckling, the initial geometrical imperfection that most influences the ultimate load is the minor-axis bending. 
Moreover, for the experimental load $v s$ axial displacement curve to be adequately achieved by the numerical simulation; all three initial geometrical imperfections shall be considered in the finite element model $\left(d_{m}, d_{M}\right.$, and $\left.\beta\right)$.

\section{REFERENCES}

[1] Rasmussen, K.J.R., Design of angle columns with locally unstable legs, J. Struct. Eng. ASCE 131 (10) (2005) 1553-1560.

[2] Dinis, P. B., Camotim, D., Silvestre, N. (2010). On the local and global buckling behaviour of angle, T-section and cruciform thin-walled members. Thin-Walled Structures, 48(1011), 786-7.

[3] Dinis, P. B., Camotim, D., \& Silvestre, N. (2012). On the mechanics of thin-walled angle column instability. Thin-Walled Structures, 52, 80-89.

[4] Dinis, P.B., Camotim, D., A novel DSM-based approach for the rational design of fixedended and pin-ended short-to-intermediate thin-walled angle columns, Thin-Walled Struct. 87 (2015) 158-182.

[5] Dinis, P.B., Camotim, D., Vieira, L., DSM design approach for hot-rolled steel angle columns ce/papers, 1, 2017 2-3. (3781-90).

[6] Landesmann, A., Camotim, D., Dinis, P.B., Cruz, R., Short-to-intermediate slender pinended cold-formed steel equal-leg angle columns: Experimental investigation, numerical simulations and DSM design, Eng. Struct. 132 (2017) 471-493.

[7] A. da S. Sirqueira, P.C.G.S. da Vellasco, L.R.O. de Lima, F.R. Sarquis, A.T. da Silva, Experimental and numerical assessments of hot-rolled carbon steel fixed-ended angles in compression. THIN-WALLED STRUCTURES, v. 157, p. 107018, 2020.

[8] Reynolds, N. A. (2013). Behaviour and Design of Concentrically Loaded Duplex Stainless Steel Single Equal-Leg Angle Struts. (August), 253.

[9] A. Menezes, P.C.G.S. da Vellasco, L.R.O. de Lima, A.T. da Silva, Experimental and numerical investigation of austenitic stainless steel hot-rolled angles under compression, J. Constr. Steel Res. 149 (2018) 1-15.

[10] Y. Liang, V.V.K. Jeyapragasam, L. Zhang, O. Zhao, Flexural-torsional buckling behaviour of fixed-ended hot-rolled austenitic stainless steel equal-leg angle section columns, J. Constr. Steel Res. 154 (2019) 43-54.

[11] L. Zhang, K. Tan, O. Zhao, Experimental and numerical studies of fixed-ended coldformed stainless steel equal-leg angle section columns, Eng. Struct. 184 (2019) 134-144.

[12] Y. Sun, L. Zhanke, L. Yating, O. Zhao, Experimental and numerical investigations of hotrolled austenitic stainless steel equal-leg angle sections, Thin-Wal. Str. 144 (2019) 1-12.

[13] F. Sarquis, L. Lima, P. Vellasco, M. Rodrigues, Experimental and numerical investigation of hot-rolled stainless steel equal leg angles under compression, Thin-Walled Struct. 151 (2020), https://doi.org/10.1016/j.tws.2020.106742.

[14] A. da S. Sirqueira, P.C.G.S. da Vellasco, L.R.O. de Lima, F.R. Sarquis, Experimental assessment of stainless steel hot-rolled equal legs angles in compression, J. Constr. Steel Res. 169 (2020), https://doi.org/10.1016/j.jcsr.2020.106069.

[15] Ansys, Inc. Theory Reference (version 17.0), 2017. 